American Journal of Applied Sciences 8 (1): 33-38, 2011

ISSN 1546-9239

(C) 2010 Science Publications

\title{
Accurate Determination of Nonlinear Refractive Index for Some Binary Glass Systems
}

\author{
ElSayed Moustafa \\ Department of Physics, Faculty of Science, El-Azaher University, Assuit, Egypt
}

\begin{abstract}
Problem statement: This study investigates the relation between the nonlinear optical susceptibility $\left(\chi^{(3)}\right)$ and the ratio $\left(\alpha_{1} / \alpha_{0-2}\right)$, then the nonlinear index determination for some binary glass systems. Recently suitable relationship between the oxidation polarizability and the nonlinear optical properties was established for simple oxides glasses. So in this study more attention and investigation is paid to the trend of that relation quantitatively as possible. Approach: The idea of the present research is how to obtain the non linear refractive index as function of ratio $\left(\alpha_{1} / \alpha_{\mathrm{o}-2}\right)$, as we know the cation polarizability $\alpha_{1}$ can be determined easy and $\alpha_{0-2}$ also can be obtained according the energy gap or the real refractive index. Consequently a proposed scale has been established between the nonlinear optical susceptibility $\left(\chi^{(3)}\right)$ and the ratio $\left(\alpha_{1} / \alpha_{0-2}\right)$ for some binary glass systems. Results: A comparison between our obtained results and the empirical method of Boling shows that there is a good agreement between them. Conclusion: The advantages of the suggested method fix on the expectation of the value $\left(\chi^{(3)}\right)$ without the complex and sensitivity experimental set-up.
\end{abstract}

Key words: Nonlinear refractive index, cation polarizability, oxide ion polarizability, nonlinear optical susceptibility, accurate determination

\section{INTRODUCTION}

Near resonance, the imaginary part of the susceptibility $\left(\chi^{(3)}\right)$ becomes important. One may argue that a part of the light beam will be absorbed near the resonance (Varshneya, 1993). As a result that the redistribution of the electron energy levels depending upon the intensity of the beam according to the following equation of refraction (Varshneya, 1993):

$\mathrm{n}(\omega)=\mathrm{n}_{0}+\gamma \mathrm{I}=\mathrm{n}_{0}+\mathrm{n}_{2}<\mathrm{E}^{2}>$

Where:

$\mathrm{n}_{0}=$ The real index of refraction

$\gamma=$ The non-linear coefficient

$\mathrm{n}_{2}=$ The non-linear refractive index

Also $\mathrm{E}$ is the rms of the electric field of the incident light beam.

The absorption frequency would then shift toward the incident beam, since the frequency shifts.

Boling et al. (2003) had estimated $\gamma$ or $\mathrm{n}_{2}$ by suggesting an experimental formula as an approximation method as follows:

$\gamma=\frac{\mathrm{k}^{\prime}\left(\mathrm{n}_{0}-1\right)\left(\mathrm{n}_{0}+1\right)}{\mathrm{n}_{0} \mathrm{\cup}_{0}\left[1.52+\frac{\left(\mathrm{n}_{0}+1\right)\left(\mathrm{n}_{0}^{2}+2\right)}{6 \mathrm{n}_{0}}\right)}$ where, $\mathrm{k}^{\prime}$ is a constant nearly $2.8^{*} 10^{-18} \mathrm{~m}^{2} / \mathrm{W}, v_{\mathrm{d}}$ is the abbi number.

On the basis of a physical nature between the cation and the oxide ion polarizability, the nonlinear optical susceptibility has been obtained as a function of the ratio $\frac{\alpha_{1}}{\alpha_{0^{-2}}}$. There is no systematic data about the correlation between the nonlinear optical properties and $\frac{\alpha_{1}}{\alpha_{0^{-2}}}$.

\section{MATERIALS AND METHODS}

The theoretical idea of this research study is that the nonlinear optical susceptibility $\chi^{(3)}$ increases with presence of the no bridging oxygen atoms in the system of glass and decreases as the system tends to the metallization state.

Theory: Optical devices, which are currently being investigated for use in computational systems and telecommunications, require materials that are characterized with large optical nonlinearity (Zhao et al., 2007). These applications require that the optical properties of the active material change in the response to an applied optical field, the magnitude of this effect being characterized by a single term called the third order susceptibility tensor, $\chi^{(3)}$ the latter can be thought of as a coefficient in a power series expansion of the 
Am. J. Applied Sci., 8 (1): 33-38, 2011

relationship between the applied electric field $\mathrm{E}$ and the polarization p (Varshneya, 1993). However the importance of the determination of the nonlinear coefficient is now necessary.

One of the most important properties of materials, which are closely related to their applicability in the field of optics and electronics, is the electronic polarizability of ions (Chimalawong et al., 2010).

Optical nonlinearity of a material is caused as it exposes to intense light beams, hence the nonlinear response of a material is controlled by the electronic polarizability (Jackson, 2003).

Accordingly, materials of high nonlinear coefficient have to be discovered on the basis of correlation of nonlinear response with some electronic properties which can be explained easily (Rekha and Ramalingam, 1970).

In this research study, the relationship between the nonlinear optical susceptibility index $\chi^{(3)}$ and the ratio $\frac{\sum \alpha_{1}}{\alpha_{0^{-2}}}$ has been investigated for some binary glass systems; hence the nonlinear refractive index $\mathrm{n}_{2}$ can be estimated according to the following Equation (Varshneya, 1993):

$$
\mathrm{n}_{2}=12 \chi / \mathrm{n}_{0}\left[\chi^{(3)}\right] \text { in (esu) }
$$

\section{RESULTS}

Tables: 1-10 illustrate the behavior of the optical susceptibility with the ratio $r=\frac{\sum \alpha_{1}}{\alpha_{0^{-2}}}$ in the cases under study, in tabular shape for many binary systems under study.

Table 1: Illustrates the calculated values of the ratio $\frac{\sum \alpha_{1}}{\alpha_{0^{-2}}}$ corresponding $\chi^{(3)} \mathrm{Bi}_{2} \mathrm{O}_{3}-\mathrm{B}_{2} \mathrm{O}_{3}$ (Dimitrov and Komatsu, 1999)

$\begin{array}{llllll}\mathrm{r}=\frac{\sum \alpha_{1}}{\alpha_{\mathrm{o}^{-2}}} & 0.435 & 0.511 & 0.609 & 0.689 & 0.787\end{array}$

\begin{tabular}{llllll}
$\chi^{(3) *} 10^{-14}$ in (esu) & 31.9 & 32.5 & 51.5 & 63.4 & 81.3 \\
\hline
\end{tabular}

Note: The ratio $\frac{\sum \alpha_{1}}{\alpha_{o^{-2}}}$ increases with increasing $\mathrm{Bi}_{2} \mathrm{O}_{3}$ conten

Table 2: Illustrates the calculated values of the ratio $\frac{\sum \alpha_{1}}{\alpha_{0^{-2}}}$ corresponding $\chi^{(3)}$ in case of $\mathrm{Sb}_{2} \mathrm{O}_{3}-\mathrm{B}_{2} \mathrm{O}_{3}$ (Dimitrov and Komatsu, 1999)

\begin{tabular}{lllllllllll}
\hline $\mathrm{r}=\frac{\sum \alpha_{1}}{\alpha_{\mathrm{o}^{-2}}}$ & 0.177 & 0.253 & 0.364 & 0.452 & 0.573 & 0.573 & 0.632 & 0.647 & 0.703 \\
$\chi^{(3) * 10^{-14}} \mathrm{in}(\mathrm{esu})$ & 4.96 & 10.6 & 16.4 & 30.2 & 35.6 & 44 & 51.5 & 65.4 & 76.2 \\
\hline
\end{tabular}

Note: The ratio $\frac{\sum \alpha_{1}}{\alpha_{0^{-2}}}$ increases with increasing $\mathrm{Sb}_{2} \mathrm{O}_{3}$ content.
Table 3: Illustrates the calculated values of the ratio $\frac{\sum \alpha_{1}}{\alpha_{0^{-2}}}$ corresponding $\chi^{(3)}$ in case of $\mathrm{La}_{2} \mathrm{O}_{3}-\mathrm{B}_{2} \mathrm{O}_{3}$ (Dimitrov and Komatsu, 1999)

\begin{tabular}{llll}
\hline $\mathrm{r}=\frac{\sum \alpha_{1}}{\alpha_{\mathrm{o}^{-2}}}$ & 0.3045 & 0.3474 & 0.3915 \\
$\chi^{(3) * 10^{-14} \text { in (esu) }}$ & 31.9 & 32.5 & 51.5 \\
\hline
\end{tabular}

Note: The ratio $\frac{\sum \alpha_{1}}{\alpha_{0^{-2}}}$ increases with increasing $\mathrm{La}_{2} \mathrm{O}_{3}$ content

Table 4:Illustrates the calculated values of the ratio $\frac{\sum \alpha_{1}}{\alpha_{0^{-2}}}$ corresponding $\chi^{(3)}$ in case of $\mathrm{Li}_{2} \mathrm{O}-\mathrm{TeO}_{2}$ (Katagiri et al., 1994)

\begin{tabular}{lrrrr}
\hline $\mathrm{r}=\frac{\sum \alpha_{1}}{\alpha_{\mathrm{o}^{-2}}}$ & 0.511 & 0.546 & 0.571 & 0.606 \\
$\chi^{(3) * 10^{-14}} \mathrm{in}(\mathrm{esu})$ & 33.00 & 42.000 & 46.000 & 52.000 \\
\hline
\end{tabular}

Note: the ratio $\frac{\sum \alpha_{1}}{\alpha_{0^{-2}}}$ increases with increasing $\mathrm{Li}_{2} \mathrm{O}$ content

Table 5: illustrates the calculated values of the ratio $\frac{\sum \alpha_{1}}{\alpha_{0^{-2}}}$ corresponding $\chi^{(3)}$ in case of $\mathrm{PbO}-\mathrm{SiO}_{2}$ (Katagiri et al., 1994)

Ratio $\frac{\sum \alpha_{1}}{\alpha_{0^{-2}}} \quad \begin{array}{llllll}0.77 & 0.969 & 1.136 & 1.325 & 1.380\end{array}$

$\begin{array}{lllll}7.10 & 12.700 & 18.100 & 23.000 & 31.100\end{array}$

$\chi^{(3) * 10^{-14}}$ in (esu)

Note: The ratio $\frac{\sum \alpha_{1}}{\alpha_{0^{-2}}}$ increases with increasing $\mathrm{PbO}$ content

Table 6: Illustrates the calculated values of the ratio $\frac{\sum \alpha_{1}}{\alpha_{0^{-2}}}$ corresponding $\chi^{(3)}$ in case of $\mathrm{PbO}-\mathrm{B}_{2} \mathrm{O}_{3}$ (Kim et al., 1993)

$\begin{array}{lllll}\text { Ratio } \frac{\sum \alpha_{1}}{\alpha_{o^{-2}}} & 0.81 & 1.08 & 1.32 & 1.48\end{array}$

$\begin{array}{lllll}\text { Nonlinear optical susceptibility } \chi^{(3)} & 5.90 & 9.70 & 12.30 & 21.40\end{array}$

Note: The ratio $\frac{\sum \alpha_{1}}{\alpha_{0^{-2}}}$ increases with increasing $\mathrm{PbO}$ content

Table 7:Illustrates the calculated values of the ratio $\frac{\sum \alpha_{1}}{\alpha_{0^{-2}}}$ corresponding $\chi^{(3)}$ in case of $\mathrm{WO}_{3}-\mathrm{TeO}_{2}(\mathrm{Kim}$ et al., 1993)

\begin{tabular}{lrrr}
\hline Ratio $\frac{\sum \alpha_{1}}{\alpha_{o^{-2}}}$ & 0.619 & 0.556 & 0.486 \\
Nonlinear optical susceptibility $\chi^{(3)}$ & 142.000 & 148.000 & 159.000 \\
\hline
\end{tabular}

Note: The ratio $\frac{\sum \alpha_{1}}{\alpha_{0^{-2}}}$ increases with decreasing $\mathrm{WO}_{3}$ content 
Table 8:Illustrates the calculated values of the ratio $\frac{\sum \alpha_{1}}{\alpha_{0^{-2}}}$ corresponding $\chi^{(3)}$ in case of $\mathrm{Ag}_{2} \mathrm{O}-\mathrm{TeO}_{2}$ (Katagiri et al., 1994)

\begin{tabular}{lrrr}
\hline $\mathrm{R}=\frac{\sum \alpha_{1}}{\alpha_{\mathrm{o}^{-2}}}$ & 0.801 & 0.843 & 0.88 \\
$\chi^{(3) * 10^{-14} \text { in }(\mathrm{esu})}$ & 120.000 & 119.000 & 110.00 \\
\hline
\end{tabular}

Note: The ratio $\frac{\sum \alpha_{1}}{\alpha_{0^{-2}}}$ increases with decreasing $\operatorname{Ag}_{2} \mathrm{O}$ content

Table 9:Illustrates the calculated values of the ratio $\frac{\sum \alpha_{1}}{\alpha_{0^{-2}}}$ corresponding $\chi^{(3}$ in case of $\mathrm{MO}_{3}-\mathrm{TeO}_{2}$ (Kim et al., 1993)

\begin{tabular}{lrrr}
\hline Ratio $\frac{\sum \alpha_{1}}{\alpha_{o^{-2}}}$ & 0.649 & 0.567 & 0.514 \\
$\chi^{(3) * 10^{-14} \text { in (esu) }}$ & 67.000 & 68.000 & 69.000 \\
\hline
\end{tabular}

Note: The ratio $\frac{\sum \alpha_{1}}{\alpha_{0^{-2}}}$ decreases with increasing $\mathrm{MO}_{3}$ content

Table 10:Illustrates the calculated values of the ratio $\frac{\sum \alpha_{1}}{\alpha_{0^{-2}}}$ corresponding $\chi^{(3)}$ in case of $\mathrm{PbO}-\mathrm{TiO}_{2}$ (Sugimoto et al., 1993)

\begin{tabular}{lrrr}
\hline Ratio $\frac{\sum \alpha_{1}}{\alpha_{o^{-2}}}$ & 0.435 & 0.536 & 0.300 \\
$\chi^{(3) * 10^{-14} \text { in (esu) }}$ & 57.000 & 110.000 & 140.000 \\
\hline
\end{tabular}

Note: The ratio $\frac{\sum \alpha_{1}}{\alpha_{0^{-2}}}$ increases with decreasing PbO content systems

\section{DISCUSSION}

It is obvious with respect to Fig. 1-6 that the nonlinear optical susceptibility $\chi^{(3)}$ increases with increasing the ratio $\frac{\sum \alpha_{1}}{\alpha_{0^{-2}}}$ for almost binary oxide glass systems, but in some oxide glass systems the $\chi^{(3)}$ decreases with increasing $\frac{\sum \alpha_{1}}{\alpha_{0^{-2}}}$. To explain the above behavior, Dimitrov and Saka (1996) have established that the nonlinear refractive increases with increasing linear refractive index and decreasing energy gap of the oxides. Also the heavy metal content such as $\mathrm{Bi}_{2} \mathrm{O}_{3}$ contributes to the polarizability of the glass system, consequently the nonlinear coefficient increases due to the high polarizability of the cations of the all molecule and easy distortion of the electron density, when applying strong electromagnetic field. At the same time there is a contribution from the oxide ion because of the high electron donor ability of the oxide ion. So the valence band is composed of $\mathrm{O}_{2} \mathrm{p}$ orbitals, this means higher optical transition probability and increase in $\chi^{(3)}$.

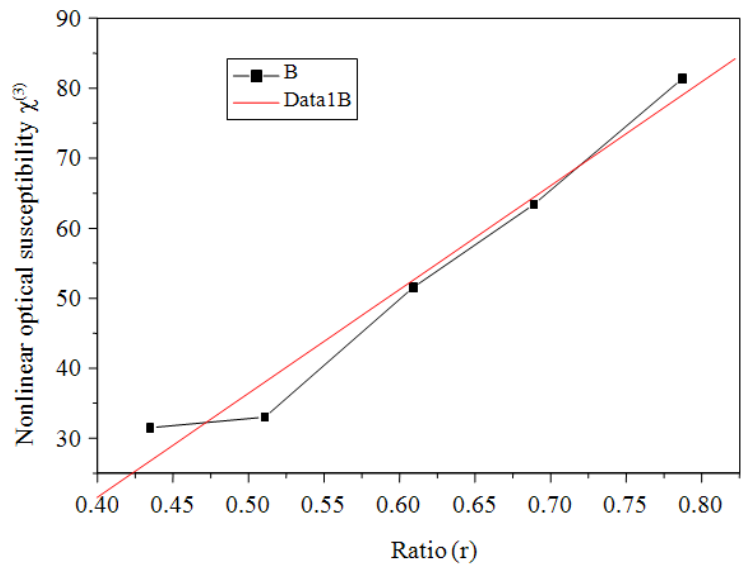

Fig. 1: Shows the relationship between the ratio $r$ and the optical susceptibility $\chi^{(3)}$ in case of $\mathrm{Bi}_{2} \mathrm{O}_{3}$ $\mathrm{B}_{2} \mathrm{O}_{3}$ system

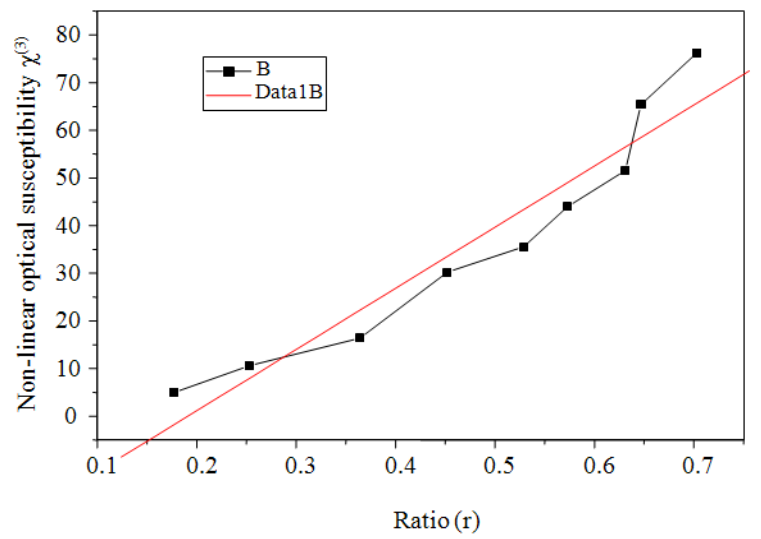

Fig. 2: Shows the relationship between the ratio $\mathrm{r}$ and $\chi^{(3)}$ in case of $\mathrm{sb}_{2} \mathrm{O}_{3}-\mathrm{B}_{2} \mathrm{O}_{3}$ system

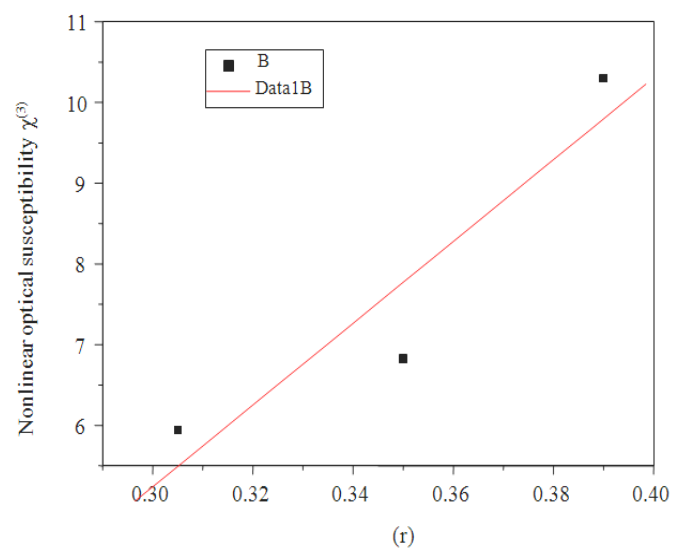

Fig. 3: Shows the relationship between the ratio $\mathrm{r}$ and the $\chi^{(3)}$ in case of $\mathrm{La}_{2} \mathrm{O}_{3}-\mathrm{B}_{2} \mathrm{O}_{3}$ 


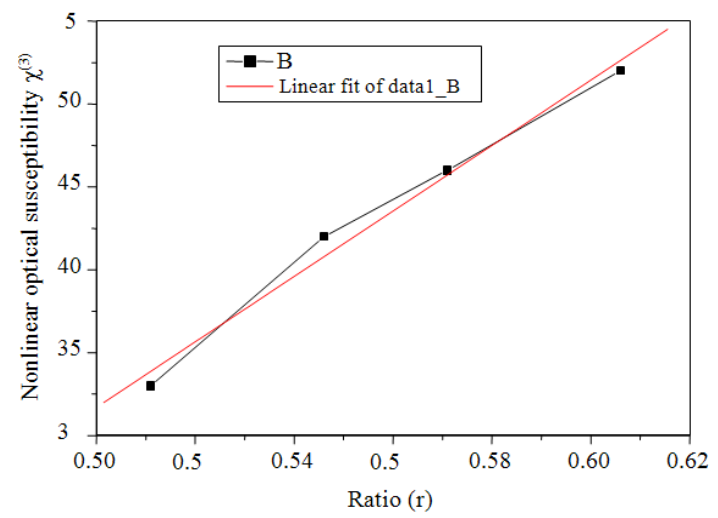

Fig. 4: Shows the relationship between the ratio in case of $\mathrm{Li}_{2} \mathrm{O}_{3}-\mathrm{TeO}_{3}$ system

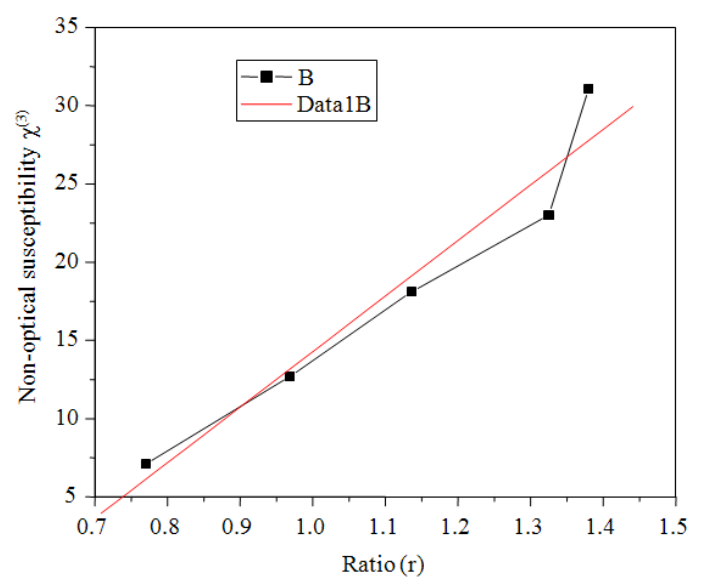

Fig. 5: Shows the relationship between the ratio $\mathrm{r}$ and the optical susceptibility $\chi^{(3)}$ in case of $\mathrm{Li}_{2} \mathrm{O}_{3}$ $\mathrm{TeO}_{3}$ system

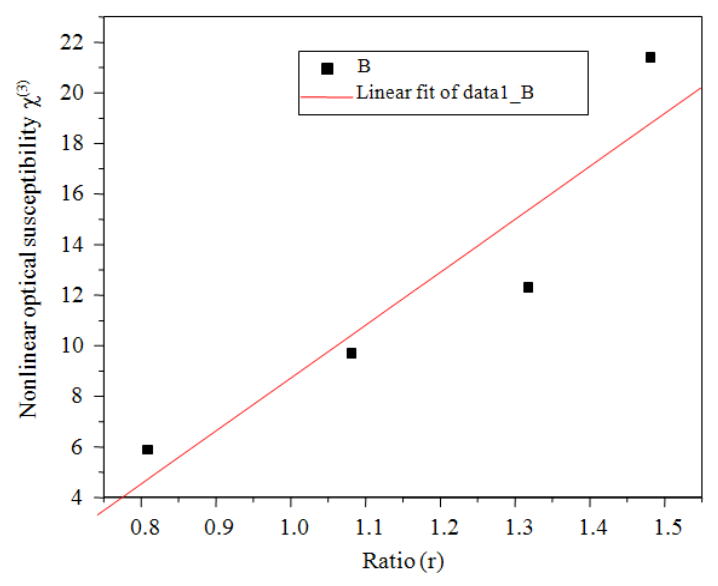

Fig. 6: Shows the relationship between the ratio in case of $\mathrm{PbO}-\mathrm{TiO}_{2}$ system

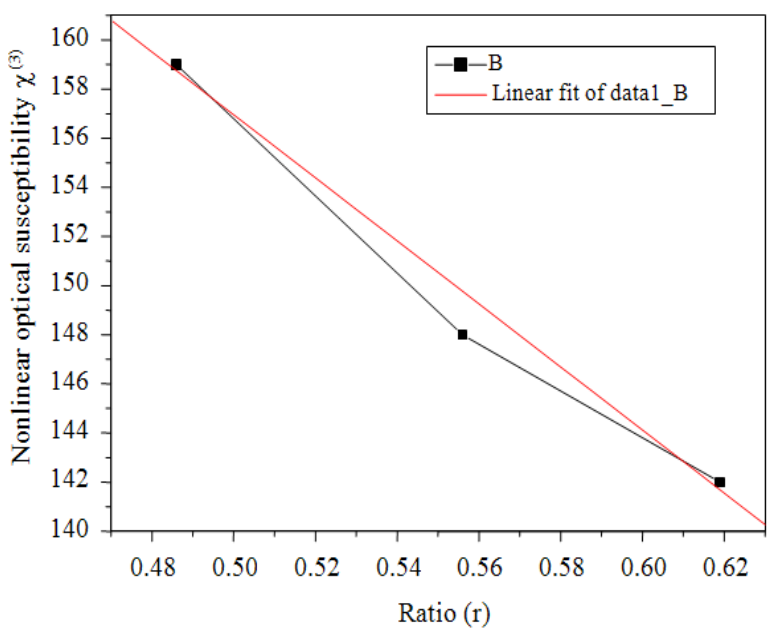

Fig. 7: Shows the relationship between the ratio $\mathrm{r}$ and the optical susceptibility $\chi^{(3)}$ in case of $\mathrm{Wo}_{3}-$ $\mathrm{TeO}_{2}$ system

According to Dimitrov et al. (1996) in Lorentz-Lorentz equation $\mathrm{R}_{\mathrm{m}} / \mathrm{V}_{\mathrm{m}} \approx 1$ corresponds to the metallization of covalent solid materials, where $R_{m}$ and $V_{m}$ are the molar refraction and volume respectively.

Dimitrov et al. (1996) suggestion was a good correlation between the energy gap of the oxides and their molar refraction, also (Dimitrov and Sakka, 1996) have been reported a data of $\mathrm{M}\left(\mathrm{E}_{\mathrm{g}}\right)$ and non-linear optical susceptibility $\chi^{(3)}$. It was found that the oxides with large non-linear refractive posses a metallization factor (criterion) smaller than the oxide glasses contain alkaline and alkaline-earth oxides such as $\mathrm{B}_{2} \mathrm{O}_{3}$ and $\mathrm{SiO}_{2}$, the two later oxides have a small non-linear optical susceptibility $\chi^{(3)}$. With respect to Fig. 7-9, although the optical susceptibility $\chi^{(3)}$ has a large value i.e., high non-linear refractive index, but as the $\mathrm{Ag}_{2} \mathrm{O}$, $\mathrm{Mo}_{3}, \mathrm{Wo}_{3}$ oxides content increases in the glass systems, $\chi^{(3)}$ decreases with increasing the ratio $\frac{\sum \alpha_{1}}{\alpha_{0^{-2}}}$ in this case. It can be explained as the relationship between non-linear optical susceptibility $\chi^{(3)}$ and the ratio $\frac{\sum \alpha_{1}}{\alpha_{0^{-2}}}$ is inversely proportional when the metallization process arises in glass system. Also with respect to Fig. 10 which illustrates the relationship between the ratio $\frac{\sum \alpha_{1}}{\alpha_{0^{-2}}}$ and $\chi^{(3)}$ for $\mathrm{PbO}-\mathrm{TiO}_{2}$ system although $\mathrm{PbO}$ in the previous cases is nearly directly proportional, but in Fig. 10 is inversely proportional with increasing $\mathrm{PbO}$ 
Am. J. Applied Sci., 8 (1): 33-38, 2011

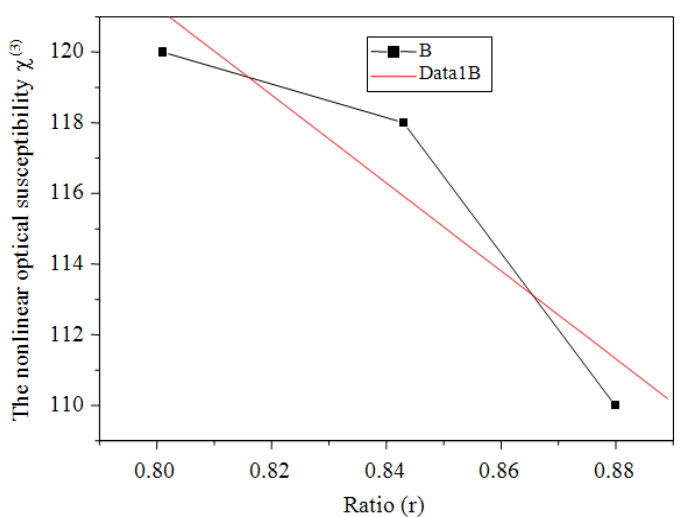

Fig. 8: Shows the relationship between the ratio $r$ and the optical susceptibility $\chi^{(3)}$ in case of $\mathrm{Ag}_{2} \mathrm{O}$ $\mathrm{TeO}_{2}$ system

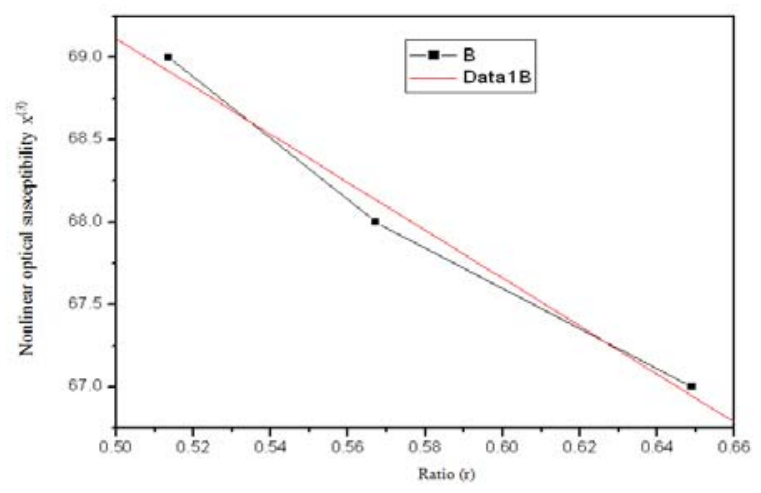

Fig. 9: Shows the relationship between the ratio $\mathrm{r}$ and the optical susceptibility $\chi^{(3)}$ in case of $\mathrm{Mo}_{3}$ $\mathrm{TeO}_{2}$ system

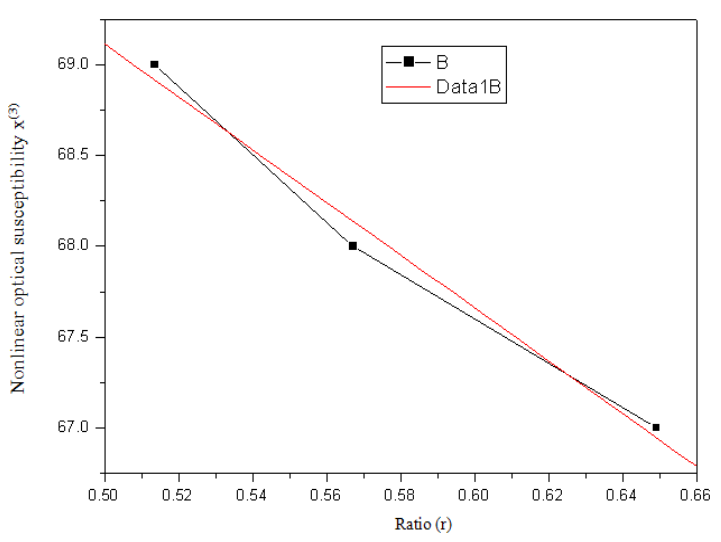

Fig. 10: Shows the relationship between the ratio $r$ and the optical suscpetebility $\chi^{(3)}$ in case of PbO$\mathrm{TiO}_{2}$ content, this because of the metallization criterion decreasing i.e., the glass tends to be metal.

Finally, it is obvious that a general formula can be suggested in order to correlate the non-linear optical susceptibility $\chi^{(3)}$ and the ratio $\frac{\sum \alpha_{1}}{\alpha_{0^{-2}}}$ as follows:

$\chi^{(3)}=\mathrm{A} \frac{\sum \alpha_{1}}{\alpha_{0^{-2}}}+\mathrm{B}$

where, $\mathrm{A}$ and $\mathrm{B}$ are constants based on the type of glass system, they can be determined from the slope of line represents the relationship between $\chi^{(3)}$ and $\frac{\sum \alpha_{1}}{\alpha_{0^{-2}}}$.

Table 11 summarizes the values of the constants $A$, $\mathrm{B}$ and the correlation factor $\mathrm{R}$ for different above binary glass systems respectively. The values of the constants of the proposed formula which correlates $\chi^{(3)}$ with $\frac{\sum \alpha_{1}}{\alpha_{0^{-2}}}$.

As an application of the above suggested method in case of $\mathrm{Bi}_{2} \mathrm{O}_{3}-\mathrm{B}_{2} \mathrm{O}_{3}$ glass system, the nonlinear refractive index calculated by Boling formula is of order $2.5^{*} 10^{-19} \mathrm{~m}^{2} / \mathrm{W}$. At the same time $\mathrm{n}_{2}=2.71 * 10^{-19}$ $\mathrm{m}^{2} / \mathrm{W}$ according to the suggested method (where $\mathrm{n}_{0}=2$ in this case ).The difference percentage nearly $\pm 7 \%$, i think that error is suitable for such measurements.

\section{CONCLUSION}

A quantitative relation between the nonlinear optical susceptibility $\chi^{(3)}$ and the ratio $\frac{\sum \alpha_{1}}{\alpha_{0^{-2}}}$ is to be expected. This is because the oxide ion represents the ability to donate negative charge when combined with a suitable cation.

Table 11 can help us and the interesting peoples in the field of studying non-linear optical properties for obtaining the corresponding values of $\chi^{(3)}$ for each individual content of binary glasses; hence $\mathrm{n}_{2}$ can be determined easily.

The above study is a trial of treatment the relationship between the nonlinear optical susceptibility and the ratio of the value of cation to the oxide ion polarizability for binary glass systems with a simulating method. 
Am. J. Applied Sci., 8 (1): 33-38, 2011

Table 11: Summarizes the values of the constants A, B and the correlation factor R for different above binary glass systems respectively. The values of the constants of the proposed formula which correlates $\chi^{(3)}$ with $\frac{\sum \alpha_{1}}{\alpha_{0^{-2}}}$.

\begin{tabular}{|c|c|c|c|c|c|c|c|c|c|c|}
\hline No of sys & 1 & 2 & 3 & 4 & 5 & 6 & 7 & 8 & 9 & 10 \\
\hline A & 148.3300 & 128.3700 & 50.6400 & 197.4090 & 35.4990 & 20.9270 & -128.3600 & -124.930 & -14.560 & -234.820 \\
\hline B & -37.7800 & -24.5400 & -9.9510 & -67.0030 & -21.2170 & -12.2090 & 220.7400 & 221.100 & 76.390 & 215.500 \\
\hline $\mathrm{R}$ & 0.9842 & 0.9612 & 0.9339 & 0.9929 & 0.9685 & 0.9281 & 0.9905 & 0.932 & 0.993 & 0.924 \\
\hline
\end{tabular}

\section{REFERENCES}

Boling, N., A. Glass and A. Owyoung, 2003. Empirical relationships for predicting nonlinear refractive index changes in optical solids. IEEE J. Quantum Electron., 14: 601-608.

Chimalawong, P., J. Kaewkhao and P. Limsuwan, 2010. Optical investigation and electronic polarizability of $\mathrm{Nd}^{3+}$ doped soda-lime-silicate glasses. Energy Res. J., 1: 176-181. DOI: 10.3844/erjsp.2010.176.181

Dimitrov, V. and S. Saka, 1996. Electronic oxide polarizability and optical basicity of simple oxides. I. J. Appl. Phys. 79: 1436 -1741. DOI: 10.1063/1.360962

Dimitrov, V. and T. Komatsu, 1999. Electronic polarizability, optical basicity and non-linear optical properties of oxide glasses. J. Non-Crystal. Solids, 249: 160-179. DOI: $10.1016 /$ S00223093(99)00317-8

Jackson, S.D., 2003. Continous wave $2.9 \mu \mathrm{m}$ dysprosium-doped fluorid fiber laser. Appl. Phy. Lett., 83: 1316. DOI: 10.1063/1.1603353

Katagiri, Y., H. Nasu, J. Matsuok and K. Kamiya, 1994. Sol-gel preparation and optical nonlinearity of lead(II) oxide-Titanium (IV) oxide amorphous monolitls. J. Am. Ceram. Soc., 77: 673-677. DOI: 10.1111/j.1151-2916.1994.tb05347.x
Kim, S.H., T. Yoko and S. Sakka, 1993. Linear and nonlinear optical properties of $\mathrm{TeO}_{2}$ glass. J. Am. Ceram. Soc., 76: 2486-2490. DOI: 10.1111/j.11512916.1993.tb03970.x

Rekha, R.K. and A. Ramalingam, 1970. Optical nonlinear proreties and optical limiting effect of metanil yellow. Am. J. Eng. Applied Sci., 2: 285-291. DOI: 10.3844/ajeassp.2009.285.291

Sugimoto, O., H. Nasu, J. Matsuoka and K. Kamiya, 1993. Computer simulation of the vibrational spectra and properties of fluoride glasses based on $\mathrm{ZrF}_{4}$. J. Non-Cryst. Solids, 161: 118-122. DOI: 10.1016/0022-3093(93)90681-M

Varshneya, A.K., 1993. Fundementals of Inorganic Glasses. 1st Edn., Academic Press, New York, ISBN-10: 0127149708, pp: 570.

Zhao, X., X. Wang, H. Lin and Z. Wang, 2007. Correlation among electronic polarizability, optical basicity and interaction parameter of $\mathrm{Bi}_{2} \mathrm{O}_{3}-\mathrm{Bi}_{2} \mathrm{O}_{3}$ glasses. Phy. B., 390: 293-300. DOI: 10.1016/j.physb.2006.08.047 